\title{
Nickel-catalysed Alkylative Alkenation of Orthothioesters with Grignard Reagents; a Convenient Procedure for introducing the Isopropenyl Group. Synthesis of Substituted 1,3-(Bis-trimethylsilyl)propenes
}

\author{
Yih-Ling Tzeng, Tien-Yau Luh,* and Jim-Min Fang \\ Department of Chemistry, National Taiwan University, Taipei, Taiwan 10764, Republic of China
}

Nickel-catalysed coupling of orthothioesters with MeMgl furnishes a general method for introducing the isopropenyl group; the application of this reaction to the synthesis of 1,3-(bis-trimethylsilyl)propenes is presented.

The use of nickel-catalysed coupling reactions of organosulphur compounds with Grignard reagents has been extensive. 1,2 We recently uncovered several useful transformations concerning dithioacetal functionality. ${ }^{3-5}$ To illustrate this, dithioacetals can couple with Grignard reagents in the presence of a catalytic amount of $\mathrm{NiCl}_{2}\left(\mathrm{PPh}_{3}\right)_{2}$ to give the corresponding alkenes. ${ }^{3}$ Allyl, vinyl, as well as butadienyl silanes are synthesized in good to excellent yields. ${ }^{3}$ In these reactions, one of the carbon-sulphur bonds is replaced by a carbon-carbon bond and the other carbon-sulphur bond undergoes elimination to yield alkenes. Orthothioesters commonly serve as latent ester groups, ${ }^{6}$ other synthetic usage of this functionality being rare. ${ }^{7}$ This function has three carbonsulphur bonds. We felt that the exploitation of the nickelcatalysed coupling reactions of orthothioesters with Grignard reagents would afford a convenient entry to the isopropenyl orthothioesters in synthesis.

In a typical procedure, orthothioester (1), readily obtained from the reaction of the anion of dithiane with dimethyldisulphide according to the literature procedure, ${ }^{6}$ was mixed with five equivalents of $\mathrm{MeMgI}$ in the presence of $\mathrm{NiCl}_{2}\left(\mathrm{PPh}_{3}\right)_{2}(5$ $\mathrm{mol} \%$ ) in benzene-ether, tetrahydrofuran (THF)-ether, or benzene alone and the mixture was heated under reflux overnight to give, after usual work-up and chromatographic separation, the coupling product (2). $\dagger$ Excess amount of the Grignard reagent was essential to achieve completion of the reaction. The results are summarized in Table 1 . Orthothioesters, having different substituents on the aryl group, gave (2) in good to excellent yields. It is noted that the aryl ether linkage has been known to react under similar conditions. ${ }^{8}$ However, substrates containing such functionality remained intact throughout this study.

Table 1. Reactions of orthothioesters with the Grignard reagent in the presence of a catalytic amount of $\mathrm{NiCl}_{2}\left(\mathrm{PPh}_{3}\right)_{2}$

\begin{tabular}{|c|c|c|c|c|c|}
\hline Substrate & $\begin{array}{l}\text { Grignard } \\
\text { reagent }\end{array}$ & $\begin{array}{c}\text { Con- } \\
\text { ditions }{ }^{a}\end{array}$ & Product & $\%$ Yield & $E: Z$ \\
\hline (1a) & $\mathrm{MeMgI}$ & A & (2a) & 83 & \\
\hline (1b) & MeMgI & A & (2b) & 73 & \\
\hline (1c) & $\mathrm{MeMgI}$ & A & (2c) & 91 & \\
\hline (1d) & MeMgI & A & (2d) & 86 & \\
\hline (1e) & $\mathrm{MeMgI}$ & B & (2e) & 69 & \\
\hline (1f) & MeMgI & B & (2f) & 69 & \\
\hline (1a) & $\mathrm{Me}_{3} \mathrm{SiCH}_{2} \mathrm{MgCl}$ & A & (4a) & 79 & $1: 3$ \\
\hline (1b) & $\mathrm{Me}_{3} \mathrm{SiCH}_{2} \mathrm{MgCl}$ & $\mathrm{C}$ & (4b) & 69 & $1: 1$ \\
\hline (1c) & $\mathrm{Me}_{3} \mathrm{SiCH}_{2} \mathrm{MgCl}$ & B & (4c) & 68 & $1.2: 2.3$ \\
\hline (1d) & $\mathrm{Me}_{3} \mathrm{SiCH}_{2} \mathrm{MgCl}$ & A & (4d) & 48 & $1: 1$ \\
\hline (1g) & $\mathrm{Me}_{3} \mathrm{SiCH}_{2} \mathrm{MgCl}$ & $\mathrm{C}$ & (4e) & 72 & $1.9: 3.6$ \\
\hline
\end{tabular}

${ }^{a} \mathrm{~A}$ : in refluxing ether-benzene. $\mathrm{B}$ : in ether-THF at room temperature. $\mathrm{C}$ : in refluxing benzene.
$: 3$

$2: 2.3$

$1: 1$

$1: 1$ groups. We decribe here an unprecedented application of

Although the actual mode of the reaction has not been established, the reaction may proceed via a similar pathway to that suggested for dithioacetals. The two carbon-sulphur bonds in (1) may first be replaced by two carbon-carbon bonds and the remaining carbon-sulphur bond may further proceed via oxidative addition with a $\mathrm{Ni}^{0}$ species to afford $(3)$ which will then undergo $\beta$-elimination giving the isopropenyl group.

The extension of this reaction to the synthesis of silylsubstituted alkenes has been carried out. When the silylsubstituted Grignard reagent is employed, it may provide an extremely facile synthesis of (4) having both allyl and vinyl silane functionalities. These products may serve as a dianion synthon (5) which could be useful in synthesis. ${ }^{9,10}$ However, (4) can generally only be obtained via a multistep synthesis requiring starting materials which are not readily accessible. ${ }^{11}$ Thus, treatment of orthothioester with five equivalents of $\mathrm{Me}_{3} \mathrm{SiCH}_{2} \mathrm{MgCl}$ and $\mathrm{NiCl}_{2}\left(\mathrm{PPh}_{3}\right)_{2}(5 \mathrm{~mol} \%)$ in refluxing benzene followed by usual work-up and flash column chromatography $\neq$ afforded (4) in satisfactory yields. $\dagger$ The $(E)$ - and $(Z)$-isomers of (4) were separated easily by preparative GLC using $10 \%$ SE30 as the stationary phase. The results are outlined in Table 1. The stereochemical assignments were based on the NMR data. The vinylic $\mathrm{Me}_{3} \mathrm{Si}$ group of the $(E)$-isomers absorbed at higher field $(\delta-0.18$ to -0.09$)$, whilst that of the $(Z)$-isomers emerged at lower field $(\delta$ $0.12-0.21)$. With the exception of $(\mathbf{4 a})$, the alkenic proton for the $(Z)$-isomers appeared at lower field $(\delta 5.41-5.64)$ than those for the $(E)$-isomers $(\delta 5.26-5.44)$. These assignments have been confirmed by NOE experiments.

Compounds (4) were highly reactive and protonolysis<smiles>CSC1([Al])SCCCS1</smiles>

$(1 \mathbf{a}-\mathbf{g})$

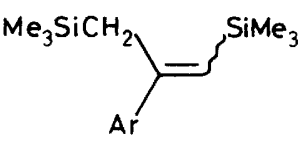

$(4 a-e)$

(1)

$\begin{array}{cc}\text { (1) } & \text { (2) } \\ \text { a } & \text { a } \\ \text { b } & \text { b } \\ \text { c } & \text { c } \\ \text { d } & \text { d } \\ \text { e } & \text { e } \\ \text { f } & \text { f } \\ \text { g } & \end{array}$<smiles>C=C(C)[Mg]</smiles>

$(2 a-f)$<smiles>C=C(C)Br</smiles>

(5)<smiles>CC(C)([AlH2])Br</smiles>

(3) $\dagger$ All new compounds gave satisfactory spectroscopic data $\left({ }^{1} \mathrm{H}\right.$ and ${ }^{13} \mathrm{C}$ NMR, and MS) and accurate mass measurement.
¥Desilylation can be avoided by using flash column chromatography for the purification of (4). 
occurred readily upon prolonged contact of (4) with silica gel leading to a significant amount of allylsilanes (6). $\ddagger$

In conclusion, we have demonstrated a simple procedure for introducing isopropenyl groups and a new facile synthetic methodology for the preparation of (4). The applications of (4) as the dianion synthon will be reported in due course. ${ }^{10}$

We thank the National Science Council of the Republic of China for support.

Received, 31st October 1989; Com. 9/04688G

\section{References}

1 H. Okamura, M. Miura, and H. Takei, Tetrahedron Lett., 1979, 43; M. Tiecco, L. Testaferri, M. Tingoli, D. Chianelli, and E. Wenkert, J. Chem. Soc., Chem. Commun., 1979, 637.

2 For a review, see: T.-Y. Luh and Z.-J. Ni, Synthesis, in the press.

3 Z.-J. Ni and T.-Y. Luh, J. Chem. Soc., Chem. Commun., 1987, 1515; 1988, 1011; J. Org. Chem., 1988, 53, 2129; 5582; D. K. P. Ng and T.-Y. Luh, J. Am. Chem. Soc., 198, 111, 9119.

4 P.-F. Yang, Z.-J. Ni, and T.-Y. Luh, J. Org. Chem., 1989, 54, 2261.
5 C. S. Wong, W. S. Leung, L. L. Yeung, and T.-Y. Luh, J. Organomet. Chem., 1986, 307, C49; L. L. Yeung, Y. C. Yip, and T.-Y. Luh, J. Chem. Soc., Chem. Commun., 1987,981; D. K.P. $\mathrm{Ng}$ and T.-Y. Luh, Tetrahedron Lett., 1988, 29, 5131; X.-j. Wang and T.-Y. Luh, J. Org. Chem., 1989, 54, 263.

6 R. A. Ellison, W. D. Woessner, and C. C. Williams, J. Org. Chem., 1972, 37, 2757; 1974, 39, 1430; W. D. Woessner, Chem. Lett., 1976, 43.

7 H. Ikehira and S. Tanimoto, Synth. Commun., 1985, 15, 7.

8 Cf. E. Wenkert, E. L. Michelotti, and C. S. Swindell, J. Am. Chem. Soc., 1979, 101, 2246.

9 M. Grignon-Dubois, J.-P. Pillot, J. Dunguès, N. Duffaut, R. Calas, and B. Henner, J. Organomet. Chem., 1977, 127, 135; P. Bourgeois, R. Calas, and G. Merault, ibid., 1977, 141, 23.

$10 \mathrm{~W}$. W. Weng and T.-Y. Luh, unpublished results.

11 R. Corriu, N. Escudie, and C. Guerin, J. Organomet. Chem., 1984, 264, 207; J. Dunogues, R. Calas, N. Ardoin, and C. Biran, ibid., 1971, 32, C31; D. Pandy-Szekeres, G. Déleris, J.-P. Pillot, and R. Calas, Tetrahedron Lett., 1980, 21, 4267; H. Watanabe, M. Saito, N. Sutou, and Y. Nagai, J. Chem. Soc., Chem. Commun., 1981, 617; L. Birkofer and T. Kühn, Chem. Ber., 1981, 14, 2293. 